\title{
Potassium Ions are More Effective than Sodium Ions in Salt Induced Peptide Formation
}

\author{
Michael V. Dubina • Sergey Yu. Vyazmin • \\ Vitali M. Boitsov • Eugene N. Nikolaev • Igor A. Popov • \\ Alexey S. Kononikhin • Igor E. Eliseev • \\ Yuri V. Natochin
}

Received: 12 December 2012 / Accepted: 17 January 2013 /

Published online: 28 March 2013

(C) The Author(s) 2013. This article is published with open access at Springerlink.com

\begin{abstract}
Prebiotic peptide formation under aqueous conditions in the presence of metal ions is one of the plausible triggers of the emergence of life. The salt-induced peptide formation reaction has been suggested as being prebiotically relevant and was examined for the formation of peptides in $\mathrm{NaCl}$ solutions. In previous work we have argued that the first protocell could have emerged in $\mathrm{KCl}$ solution. Using HPLC-MS/MS analysis, we found that $\mathrm{K}^{+}$is more than an order of magnitude more effective in the $L$-glutamic acid oligomerization with 1,1'-carbonyldiimidazole in aqueous solutions than the same concentration of $\mathrm{Na}^{+}$, which is consistent with the diffusion theory calculations. We anticipate that prebiotic peptides could have formed with $\mathrm{K}^{+}$as the driving force, not $\mathrm{Na}^{+}$, as commonly believed.
\end{abstract}

Keywords Potassium $\cdot$ Sodium $\cdot$ Prebiotic $\cdot$ Peptide formation $\cdot$ Origin of life

\section{Introduction}

Since Oparin's ideas $(1924 ; 1938)$ and Miller-Urey's famous experiment (1953) on the prebiotic synthesis of amino acids, one of the main problems of prebiotic chemistry is to "re-invent" the plausible range of indispensable physical-chemical boundary requirements that would enable the emergence of stable and replicable molecules on the primordial Earth (Eschenmoser 2003). According to almost all discussions of the prebiotic soup theory, biological precursor molecules might have formed and evolved

M. V. Dubina $(\bowtie) \cdot$ S. Y. Vyazmin $・$ V. M. Boitsov $\cdot$ I. E. Eliseev

St. Petersburg Academic University - Nanotechnology Research and Education Centre RAS, 8/3 Khlopin str., 194021 St. Petersburg, Russia

e-mail: dubina@spbau.ru

E. N. Nikolaev $\cdot$ I. A. Popov $・$ A. S. Kononikhin

Institute for Energy Problems of Chemical Physics RAS, 38/2 Leninsky pr., 119334 Moscow, Russia

Y. V. Natochin

Institute of Evolutionary Physiology and Biochemistry RAS, 44 Torez pr., 194223 St. Petersburg, Russia 
in the context of the sodium chloride ocean on primordial Earth (Fox 1960; Rode 1999; Zimmer 2009). Salt-induced peptide formation reaction has been suggested to be prebiotically relevant for the very first steps of chemical evolution (Schwendinger and Rode 1989). Based on Monte Carlo computer simulations, Rode and co-workers found that sodium chloride at concentrations above $3 \mathrm{M}$ effectively acts as a dehydrating agent to overcome the thermodynamic barrier of peptide bond formation in aqueous solutions, and the first hydration shell of the sodium ion was assumed to no longer be saturated with water molecules (Jakschitz and Rode 2012). Furthermore, using HPLC-MS/MS analysis, a high concentration of sodium chloride was found to significantly enhance the formation of peptides from $L$-glutamic acid ( $L$-Glu) in homogenous water solutions (Wang et al. 2005).

All the references we have found that discuss the presence of other mono- and divalent inorganic cations in prebiotic peptide formation speculate that these ions support the dehydrating effect of sodium chloride. However, the level of potassium exceeds that of sodium by more than an order of magnitude inside all living cells (Aronson et al. 2009), and the ion ratio is actively preserved with $\mathrm{Na}^{+} / \mathrm{K}^{+}$pumps in the cell membrane, which suggests that potassium is more essential for life. The physicalchemical differences between $\mathrm{Na}^{+}$and $\mathrm{K}^{+}$are small (Freedman 1995), although the biodirected activity of these ions differs dramatically; for example, $\mathrm{K}^{+}$is required for ribosomal peptide synthesis (Spirin and Gavrilova 1971) and the amplification of DNA with thermostable Taq polymerase (Saiki et al. 1988), whereas $\mathrm{Na}^{+}$attenuates these processes. The contradiction between the $\mathrm{Na}^{+}$and $\mathrm{K}^{+}$compositions of seawater and living cell cytoplasm led to the hypothesis that the first protocell could have emerged in $\mathrm{KCl}$ solution (Natochin 2007; Natochin 2010). However, the hypothesis of the $\mathrm{K}^{+}$driven emergence of prebiotic peptides remains to be tested. Here we investigate the relative effects of $\mathrm{Na}^{+}$and $\mathrm{K}^{+}$in a model peptide synthesis reaction.

\section{Methods}

$L$-glutamic acid and 1,1'-carbonyldiimidazole (CDI) were obtained from Sigma-Aldrich Co. LLC (St. Louis, USA). In total, $10 \mathrm{mmol} \mathrm{KCl}$ or $10 \mathrm{mmol} \mathrm{NaCl}$ was added to reaction mixtures containing $3 \mathrm{mmol} L$-Glu in $5 \mathrm{ml}$ distilled water. The mixture was diluted to $10 \mathrm{ml}$ and cooled on a crashed ice- $\mathrm{NaCl}$ mixture, and $6 \mathrm{mmol} \mathrm{CDI}$ was added into each mixture and incubated at room temperature for $24 \mathrm{~h}$. A $10 \mu \mathrm{l}$ sample was loaded onto a Zorbax SAX $(4.6 \mathrm{~mm} \times 250 \mathrm{~mm}$, $5 \mu \mathrm{m}$ ) column using an autosampler.

Peptide separation was performed at a flow rate of $0.5 \mathrm{ml} / \mathrm{min}$ using an $\mathrm{NaCl}$ gradient (2-80\% B for $80 \mathrm{~min}$; buffer A: $20 \%$ acetonitrile in $0.020 \mathrm{M} \mathrm{NaH}_{2} \mathrm{PO}_{4}$ at pH7.0; buffer B: $2.0 \mathrm{M} \mathrm{NaCl}$ in buffer A) using an Agilent 1100 nano-HPLC system (Agilent Technologies Inc., USA). LC analysis of the peptides was performed by an established procedure (Ishihama et al. 2002) on a homemade 12-cm reverse-phase spraying fused silica capillary column $(75 \mu \mathrm{m}$ i.d. $\times 12 \mathrm{~cm})$ with a $3-\mu \mathrm{m}$ ReproSil-Pur Basic-C18 (Dr. Maisch HPLC GmbH, Germany). Peptide fractions were collected for further analysis.

MS/MS analysis of the samples was performed using a 7-Tesla LTQ-FT Ultra mass spectrometer and Xcalibur software in data-dependent mode (Thermo Fisher Scientific Inc., USA). The precursor ion MS spectra were acquired in the ICR trap with a resolution of 50,000 at $\mathrm{m} / \mathrm{z} 400$. The three most intense ions were isolated from MS/MS spectra and fragmented in LTQ. Oligomers from 2- to 9-mers were identified 
with ESI-MS. Other oligomers were assigned based on the one-charge increase in oligomers on HPLC traces.

We used the basic theories of catalytic reactions and nucleation (Dubrovskii and Nazarenko 2010) to model the ion-mediated condensation of amino acids in the liquid phase.

\section{Results}

\section{Liquid Chromatography and Mass Spectrometry}

We first prepared $L$-Glu oligomerization reactions in the presence of $1.0 \mathrm{M} \mathrm{KCl}$ based on an established procedure using CDI, followed by HPLC-MS/MS analysis. CDI is an efficient dehydrating agent that can be used to produce homooligopeptides or random oligopeptides in water via a carboxyanhydride intermediate as a route for the prebiotic activation of amino acids to form oligopeptides (Brack 1987; Hill and Orgel 1996). In the control reaction, we added $1.0 \mathrm{M} \mathrm{NaCl}$, which is the most effective salt concentration for the CDI-mediated formation of peptides (Wang et al. 2005). The chromatograms of the reactions with $1.0 \mathrm{M} \mathrm{KCl}$ or $1.0 \mathrm{M} \mathrm{NaCl}$ or no salts are shown in Fig. 1.

We found that the lengths of the oligomers increased up to 11-mer in the presence of $\mathrm{K}^{+}$ compared to 9 -mer in the presence of $\mathrm{Na}^{+}$. For the mass spectra of the oligomers, see Table 1. We then studied $L$-Glu oligomerization in the presence of $0.5 \mathrm{M}$ and $2.0 \mathrm{M} \mathrm{KCl}$ and $\mathrm{NaCl}$. We found that ion concentrations below and above $1.0 \mathrm{M}$ reduced $L$-Glu peptide yields. $\mathrm{K}^{+}$predominance was found in all the reactions.

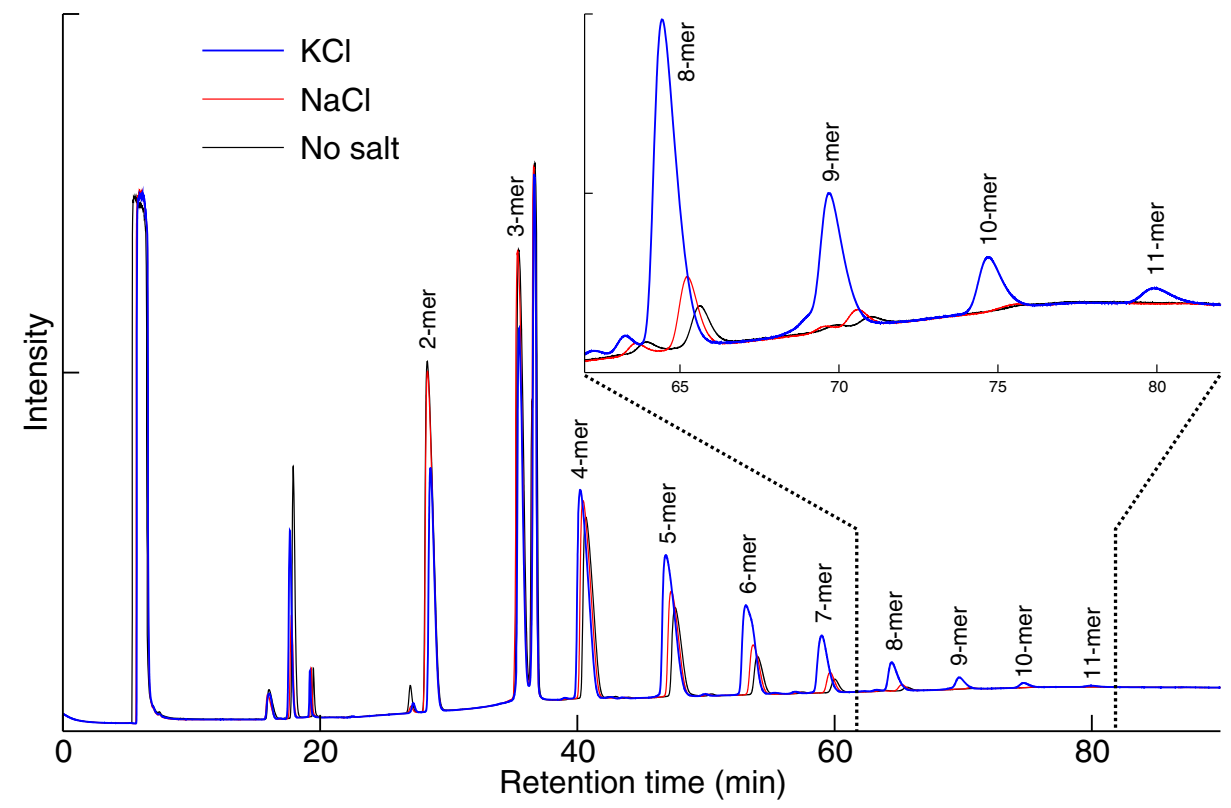

Fig. 1 Chromatograms of the $\mathrm{K}^{+}$- and $\mathrm{Na}^{+}$-mediated oligomerization of peptides. Each peak matched specific CDI-induced $L$-Glu peptides in $1.0 \mathrm{M} \mathrm{KCl}$ or $1.0 \mathrm{M} \mathrm{NaCl}$ solution or water without any salts 


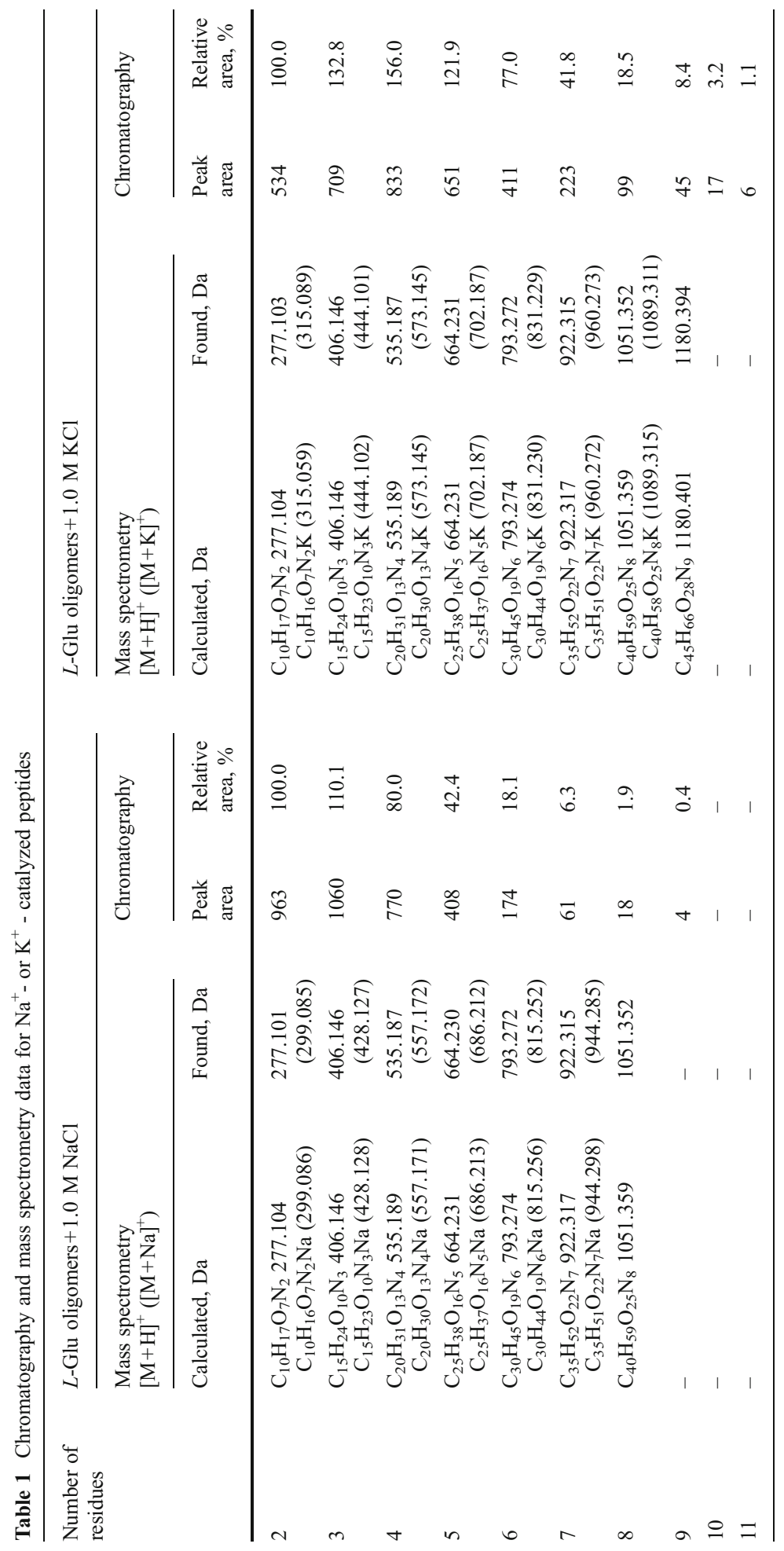


Physical Model

To provide theoretical evidence in favour of the difference between the peptide formation reactions in the presence of $\mathrm{K}^{+}$and $\mathrm{Na}^{+}$, we modelled the ion-mediated condensation of amino acids in the liquid phase. In general, the reaction chain producing the complexes $A_{n}$ with $n$ monomers in presence of a catalyst $B$ can be put in the form

$$
A_{n}+A_{1} \stackrel{B}{\longleftrightarrow} A_{n+1}
$$

This assumes the effective absence of interactions between the complexes as well as three-body interactions, the properties that should pertain for a dilute solution in water. The catalyst is assumed to promote the monomer attachment via one of the following heterogeneous reactions

$$
\begin{aligned}
& A_{1}+B \rightarrow\left[A_{1} B\right]+A_{n} \rightarrow A_{n+1}+B \\
& A_{n}+A_{1} \rightarrow\left[A_{n} A_{1}\right]+B \rightarrow A_{n+1}+B
\end{aligned}
$$

In scheme (2), the heterogeneous complex $\left[A_{1} B\right]$ is long-lived, and the growth is controlled by the diffusion transport of the reactants. Scheme (3) assumes that the homogeneous complex $\left[A_{n} A_{1}\right]$ is long-lived, where the growth should be limited by the diffusion transport of the catalyst. We considered the conventional quasi-chemical nucleation model for the concentrations $C_{n}$ of complexes containing $n$ monomers at time $t$

$$
\begin{gathered}
\frac{d C_{n}(t)}{d t}=J_{n}-J_{n+1} \\
J_{n}=W_{n-1}^{+} C_{n-1}-W_{n}^{-} C_{n}
\end{gathered}
$$

whereas, $W_{n}^{+}, W_{n}^{-}$denote the $B$-dependent rate constants for the monomer attachment and detachment, respectively, and $J_{n}$ represents the corresponding flux. The monomer concentration is generally obtained from the mass conservation $\sum_{n>1} n C_{n}=C_{\text {tot }}=$ const at any time, where $C_{t o t}$ is the total concentration of monomers in the system. In according to the nucleation theory (Dubrovskii and Nazarenko 2010) the time scale hierarchy of the entire agglomeration process results in a rather slow time dependence of the monomer concentration $C_{1}(t)$, while the concentrations of differently sized complexes depend on time only through $C_{1}(t)$. For small enough $n$, the $C_{n}$ can be obtained within the quasi-equilibrium approximation relating to $J_{n}=0$. This yields the size distribution of the form

$$
C_{n}=\prod_{i=1}^{n-1}\left(W_{i}^{+} / W_{i+1}^{-}\right) C_{1}
$$

Now we assume that the equilibrium constant $W_{i}^{+} / W_{i+1}^{-}$is proportional to a certain characteristic $b$ that depends on the catalyst type

$$
W_{i}^{+} / W_{i+1}^{-}=k_{i} b
$$


Substitution of equation (7) into equation (6) readily gives

$$
C_{n}=K_{n} b^{n-1} C_{1}
$$

whereas, dependence of the complexes concentration $C_{n}$ on the catalyst is described by the $b^{n-1}$ and $K_{n}=\prod_{i=1}^{n-1} k_{i}$ can be considered as being catalyst-independent.

The theoretical model above can be used to obtain dependence of the $L$-Glu peptides concentration on the peptide length in presence of ions, if we consider the monomer is $L$-Glu and the catalyst $B$ is $\mathrm{K}^{+}$or $\mathrm{Na}^{+}$. In case of reaction (2), the dependence might be explained with different ion adsorption probabilities onto the surface of the amino acid. For the reaction (3), the equilibrium constant $W_{i}^{+} / W_{i+1}^{-}$should be proportional to the diffusion coefficient $D_{\mathrm{K}^{+}}$or $D_{\mathrm{Na}^{+}}$of the corresponding ion in water. The diffusion limit gives the equation (9) for the ratio of peptide concentrations in the presence of $\mathrm{K}^{+}$or $\mathrm{Na}^{+}$in water solutions

$$
\frac{\left[\text { Peptide }_{K^{+}}\right]}{\left[\text {Peptide }_{\mathrm{Na}^{+}}\right]}=\left(\frac{D_{\mathrm{K}^{+}}}{D_{\mathrm{Na}^{+}}}\right)^{\text {length }-1}
$$

whereas, $\left[\right.$ Peptide $\left._{K^{+}}\right]$and $\left[\right.$Peptide $\left._{\mathrm{Na}^{+}}\right]$are concentrations of the peptides, $\mathrm{D}_{\mathrm{K}^{+}}$and $\mathrm{D}_{\mathrm{Na}^{+}}$ are diffusion coefficients of the ions in water and length is the number of $L$-Glu residues in the peptide.

Thus, the equation (9) above, with the diffusion coefficients of $\mathrm{K}^{+}\left(\mathrm{D}_{\mathrm{K}}{ }^{+}=1.957 \times 10^{-5} \mathrm{~cm}^{2} / \mathrm{s}\right)$ and $\mathrm{Na}^{+}\left(\mathrm{D}_{\mathrm{Na}}{ }^{+}=1.334 \times 10^{-5} \mathrm{~cm}^{2} / \mathrm{s}\right)$ in water solutions (Lide and David, 1998), clearly corresponds to the $\mathrm{K}^{+} / \mathrm{Na}^{+}$ratio of the salt-mediated formation of $L$-Glu peptides (Fig. 2), which was calculated as the peak area of each oligomer on the chromatogram divided by the peak area of the dipeptide in the same reaction (Table 1).

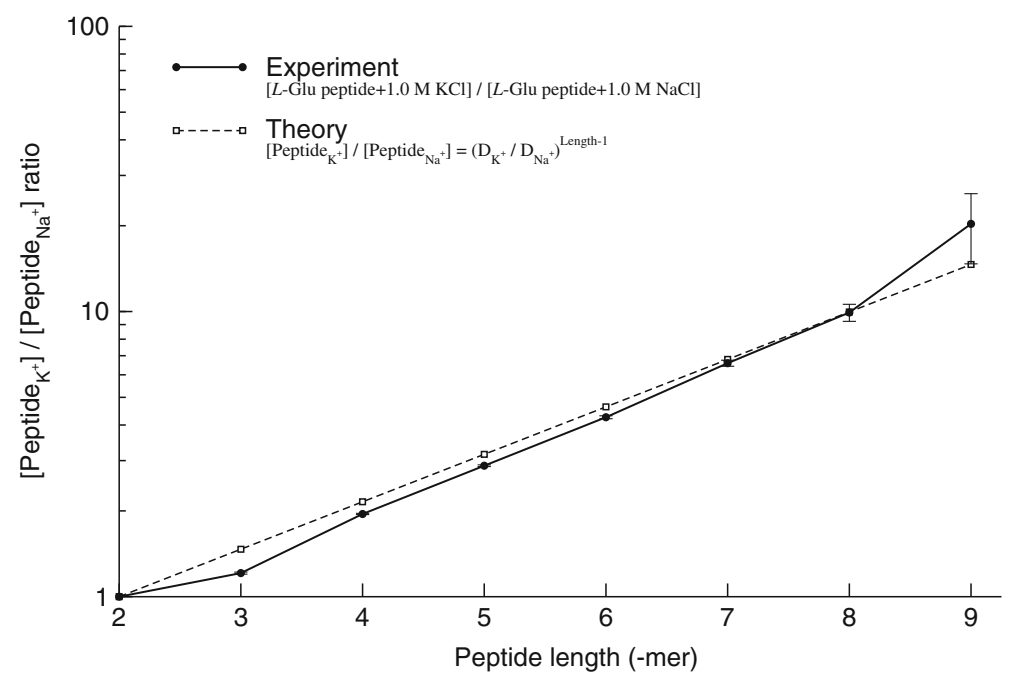

Fig. 2 Experimental and theoretical evidence of the $\mathrm{K}^{+}$- versus $\mathrm{Na}^{+}$-mediated formation of peptides The experimental data for the $\mathrm{K}^{+} / \mathrm{Na}^{+}$ratio of $L$-Glu peptides was calculated from Fig. 1 as the peak area of each oligomer on the chromatogram divided by the peak area of the dipeptide in the same reaction 


\section{Discussion}

Our experimental results demonstrate that $\mathrm{K}^{+}$has a 3-fold to 10 -fold greater catalytic effect than the same concentration of $\mathrm{Na}^{+}$on the reaction peak of 5-mer to 8-mer $L$-Glu condensation in aqueous solutions. Computations and blackbody infrared radioactive dissociations have shown that $\mathrm{Na}^{+}$is coordinated to the nitrogen and carbonyl oxygen atoms ( $\mathrm{NO}$ coordination) of amino acids, whereas $\mathrm{K}^{+}$is coordinated to both oxygen atoms (OO coordination), with lower binding energy (Jockusch et al. 2001). This finding allows us to suggest that NO coordination decreases the reactivity of amino acids for each subsequent peptide bond formation, as it begins with a nucleophilic attack on the lone electron pair of the $\mathrm{N}$ atom, in full agreement with our obtained experimental data showing the weaker $\mathrm{Na}^{+}$-mediated formation of $L$-Glu peptides.

Although the mechanism described above explains the results of the experimental $L$-Glu peptide formations in the presence of $\mathrm{K}^{+}$and $\mathrm{Na}^{+}$, this interpretation of the mechanism is not exhaustive. Our data on the calculated difference between the $\mathrm{K}^{+}$and $\mathrm{Na}^{+}$diffusioncontrolled condensation of amino acids is fully consistent with the experimental data (Fig. 2). Using the model above for other mono- and divalent ions, we summarised in Fig. 3 the available data on diffusion coefficients, hydration energy of the ions and their coordination to the amino acids in aqueous solutions (Lide and David 1998; Schmid et al. 2000; Jockusch et al. 2001; Remko and Rode 2006). We found that $\mathrm{Rb}^{+}$and $\mathrm{Cs}^{+}$might be similar to $\mathrm{K}^{+}$in mediating peptide formation in the $\mathrm{OO}$ coordination to amino acids, which has not yet been modelled, to the best of our knowledge.

Taken together, our experimental and theoretical evidences show that $\mathrm{K}^{+}$predominates over $\mathrm{Na}^{+}$ions in the formation of peptides. This allows us to suggest that the high $\mathrm{K}^{+} / \mathrm{Na}^{+}$ ratio in any prebiotic water reservoir could accelerate the first step in the chemical evolution of self-assembling organic molecules. Geochemically, a high $\mathrm{K}^{+} / \mathrm{Na}^{+}$ratio in aqueous solution could also have formed during the differentiation of primary chondritic material into the Earth's core and mantle (Galimov et al. 2011). It was also suggested that the ion composition required for the initial environment for the first cells could have emerged in inland geothermal ponds (Mulkidjanian et al. 2012). Although this assumption has been

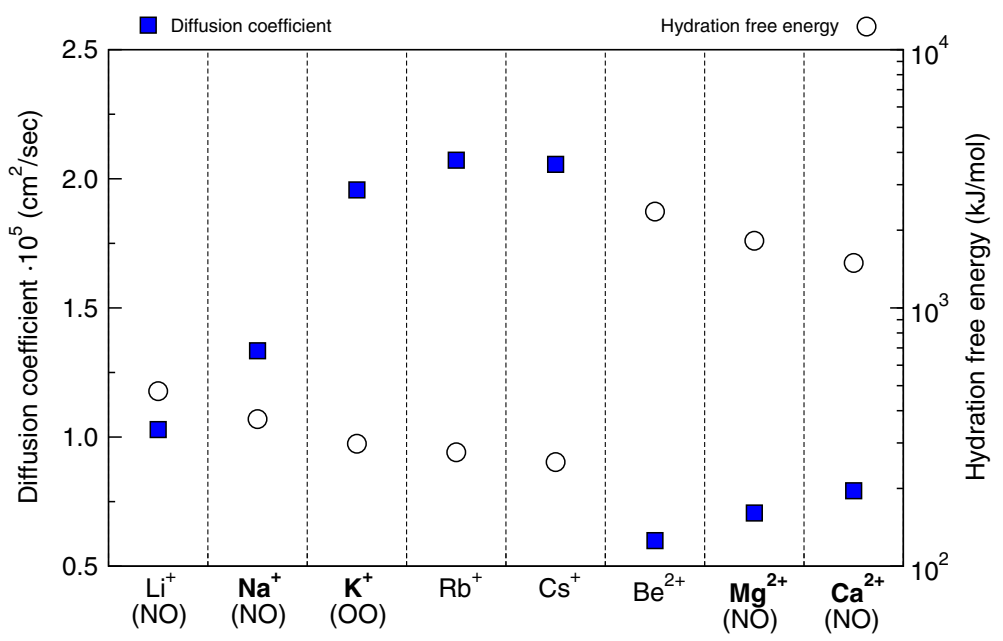

Fig. 3 Metal ion diffusion, hydration and coordination to amino acids. The coordination of the ions to amino acids in aqueous solutions is shown in parentheses. The most abundant ions are shown in bold 
criticised (Switek 2012), from a biological point of view, the "modern" cytoplasm of the living cells might represent the same functional conditions that determined the first protocell's chemical content. Thus, if the emergence of the ancient metabolic and information systems of the protocells occurred in potassium-rich habitats, it seems evident that all the living cells would have evolved to preserve the initial ion gradients by using energydependent membrane pumps in sodium aqueous media.

\section{Conclusion}

In conclusion, we hypothesise that the following conditions could have led to the prebiotic polymerisation of amino acids: (1) aqueous media contained the building blocks of organic matter and positive inorganic ions, which are geochemically abundant; (2) binding reversibility to amino acids and the moderate hydration energy of the ions in liquid phase at 0 $100{ }^{\circ} \mathrm{C}$; and (3) high diffusion and specific ion coordination to oxygen atoms of amino acids in zwitterion form, which enhances the ion-dependent yields of oligomerization. We propose that $\mathrm{K}^{+}$complies with all the above-listed requirements, which is unique in contrast to other mono- and divalent metallic ions (Fig. 3). Further peptide evolution at later stages could have occurred due to the presence of other abundant cations, e.g., $\mathrm{Na}^{+}, \mathrm{Mg}^{2+}$ and $\mathrm{Ca}^{2+}$, which may have resulted from their lower diffusion and higher hydration energy. The elongation and functionalization of the peptides might also have been driven by other inorganic cations or clays or minerals (Ferris et al. 1996; Hill and Orgel 1999; Rode et al. 1999; Rees and Howard 2003) because they form more stable complexes with biomolecules.

We assume that our findings could be useful not only for discussions of the origin of life but also for more sophisticated research on the role of the physical-chemical properties of inorganic ions, biomolecules and nanoparticles in molecular physiology. The data on the difference in $\mathrm{K}^{+}$versus $\mathrm{Na}^{+}$coordination- and diffusion-controlled condensation of amino acids may be of particular interest in understanding ion-exchange regulation by the membrane $\mathrm{Na}^{+} / \mathrm{K}^{+}$-ATPase pump.

Acknowledgments We are grateful to Prof. Yuri V. Trushin and Prof. Vladimir G. Dubrovskii for helpful discussions of the physics of diffusion, Dr. Viktor G. Zgoda for his discussions of mass spectrometry and PhD student Ivan N. Terterov for his technical assistance. This work was performed under a grant from the Presidium of the Russian Academy of Sciences.

Open Access This article is distributed under the terms of the Creative Commons Attribution License which permits any use, distribution, and reproduction in any medium, provided the original author(s) and the source are credited.

\section{References}

Aronson PS, Boron WF, Boulpaep EL (2009) Transport of solutes and water. In: Boron WF, Boulpaep EL (eds) Medical physiology, 2nd edn. Saunders Elsevier, Philadelphia, pp 106-146

Brack A (1987) Selective emergence and survival of early polypeptides in water. Orig Life Evol Biosph 17:367-379

Dubrovskii VG, Nazarenko MV (2010) Nucleation theory beyond the deterministic limit. I. The nucleation stage. J Chem Phys 132:114507

Eschenmoser A (2003) The search for the chemistry of life's origin. Tetrahedron 63:12821-12844

Ferris LP, Hill AR Jr, Liu R, Orgel LE (1996) Synthesis of long prebiotic oligomers on mineral surfaces. Nature 381:59-61 
Fox SW (1960) How did life begin? Science 132:200-208

Freedman J (1995) In: Sperelakys N (ed) Cell physiology, source book. Biophysical chemistry of cellular electrolytes. Academic, San Diego, pp 3-17

Galimov EM, Ryzhenko BN, Cherkasova EV (2011) Estimation of the composition of the Earth's primary aqueous phase. 2. Synthesis from the mantle and igneous rock material. Comparison with synthesis from the carbonaceous chondrite material. Geochem Int 49:1057-1071

Hill AR Jr, Orgel LE (1996) Oligomerization of negatively-charged amino acids by carbonyldiimidazole. Orig Life Evol Biosph 26:539-545

Hill AR Jr, Orgel LE (1999) Oligomerization of L-gamma-carboxyglutamic acid. Orig Life Evol Biosph 29:115-122

Ishihama Y, Rappsilber J, Andersen JS, Mann M (2002) Microcolumns with self-assembled particle frits for proteomics. J Chromatogr A 979:233-239

Jakschitz TA, Rode BM (2012) Chemical evolution from simple inorganic compounds to chiral peptides. Chem Soc Rev 41:5484-5489

Jockusch RA, Lemoff AS, Williams ER (2001) Effect of metal ion and water coordination on the structure of a gas-phase amino acid. J Am Chem Soc 123:12255-12265

Lide DR, David R (1998) CRC handbook of chemistry and physics, 87th edn. CRC Press, FL, pp 76-78

Miller SL (1953) A production of amino acids under possible primitive Earth conditions. Science 117:527528

Mulkidjanian AY, Bychkov AY, Dibrova DV, Galperin MY, Koonin EV (2012) Origin of first cells at terrestrial, anoxic geothermal fields. Proc Natl Acad Sci USA 109:E821-E830

Natochin YV (2007) The physiological evolution of animals: sodium is the clue to resolving contradictions. Her Russ Acad Sci 77:581-591

Natochin YV (2010) The origin of membranes. Paleontol J 44:860-869

Oparin AI (1924) Proiskhozhdenie Zhizny. Moskovski Rabochii, Moscow

Oparin AI (1938) The origin of life. Macmillan, New York

Rees DC, Howard JB (2003) The interface between the biological and inorganic worlds: iron-sulfur metalloclusters. Science 300:929-931

Remko M, Rode BM (2006) Effect of metal ions ( $\mathrm{Li}^{+}, \mathrm{Na}+, \mathrm{K}+, \mathrm{Mg} 2+, \mathrm{Ca} 2+, \mathrm{Ni2}+, \mathrm{Cu} 2+$, and $\left.\mathrm{Zn} 2+\right)$ and water coordination on the structure of glycine and zwitterionic glycine. J Phys Chem A 110:1960-1967

Rode BM (1999) Peptides and the origin of life. Peptides 20:773-786

Rode BM, Son HL, Suwannachot Y (1999) The combination of salt induced peptide formation reaction and clay catalysis: a way to higher peptides under primitive conditions. Orig Life Evol Biosph 29:273-286

Saiki RK, Gelfand DH, Stoffel S, Scharf SJ, Higuchi R, Horn GT, Mullis KB, Erlich HA (1988) Primerdirected enzymatic amplification of DNA with a thermostable DNA polymerase. Science 239:487-491

Schmid R, Miah AM, Sapunov VN (2000) A new table of the thermodynamic quantities of ionic hydration: values and some applications (enthalpy-entropy compensation and Born radii). Phys Chem Chem Phys 2:97-102

Schwendinger MG, Rode BM (1989) Possible role of copper and sodium chloride in prebiotic evolution of peptides. Analyt Sci 5:411-414

Spirin AS, Gavrilova LP (1971) Ribosome, 2nd edn. Nauka, Moscow

Switek B (2012) Debate bubbles over the origin of life. Nature. doi:10.1038/nature.2012.10024

Wang K-J, Yao N, Li C (2005) Sodium chloride enhanced oligomerization of L-glutamic acid in aqueous solution. Orig Life Evol Biosph 35:313-322

Zimmer C (2009) Evolutionary roots. On the origin of life on earth. Science 323:198-199

\section{Author Contributions}

MVD and YuVN developed the concept and supervised the project, MVD designed the experiments, interpreted the data, proposed conclusions and wrote the manuscript, YuVN provided conceptual advice; SYuV and VMB performed the experiments, analysed the data of liquid chromatography and mass spectrometry; IEE designed the theoretical model; and ENN, IAP and ASK gathered the HPLC-MS/MS data. 